\title{
Slur Reclamation - Polysemy, Echo, or Both?
}

\author{
Zuzanna Jusińska*
}

Received: 18 November 2020 / $1^{\text {st }}$ Revised: 14 May $2021 /$

$2^{\text {nd }}$ Revised: 9 July 2021 / Accepted: 8 August 2021

\begin{abstract}
This paper concerns the topic of slur reclamation. I start with presenting two seemingly opposing accounts of slur reclamation, Jeshion's (2020) Polysemy view and Bianchi's (2014) Echoic view. Then, using the data provided by linguists, I discuss the histories of the reclamation of the slur 'queer' and of the n-word, which bring me to presenting a view of reclamation that combines the Polysemy view and Echoic view. The Combined view of slur reclamation proposed in this paper postulates meaning change while fleshing out the pragmatic mechanisms necessary for it to occur.
\end{abstract}

Keywords: Meaning change; pragmatics; reclamation; semantics; slurs.

\section{Introduction}

The goal of this paper is to explore the topic of slur reclamation. It seems that explaining slur reclamation via pragmatic mechanisms competes with accounts which posit a semantic ambiguity between the derogatory and the reclaimed slur. I argue that these views are not rivals; they complement each other. I claim that it is impossible to explain meaning change

* University of Warsaw

(1) https://orcid.org/0000-0002-9490-6799

Krakowskie Przedmieście 26/28, 00-927 Warszawa, Poland.

z.jusinska@uw.edu.pl

(C) The Author. Journal compilation (c) The Editorial Board, Organon F. 
without appealing to pragmatic mechanisms, especially in the case of slur reclamation, given the socio-political motivation of this process.

In sections 2 and 3 I present two accounts of slur reclamation, Jeshion's (2020) Polysemy view and Bianchi's (2014) Echoic view. Section 4 consists of a discussion of the histories of reclaiming the slur 'queer' and of the nword. In the $5^{\text {th }}$ section, I propose a view of slur reclamation that combines the Polysemy and Echoic accounts.

\section{Jeshion's Polysemy view}

Jeshion (2020) distinguishes two most common variants of slur reclamation - pride reclamation (such as in the reclamation of 'queer') and insular reclamation (such as in the reclamation of the n-word). She defines pride reclamation as "the reclamation of a pejorative representation through processes in which the representation is accompanied by expressions of pride for being in the group or the targeted object, and the representation is presented publicly as an apt way to reference the group" (2020, 107); and insular reclamation as "the reclamation of a pejorative representation through processes in which use of the representation dominantly functions to express and elicit camaraderie among target members in the face of and to insulate from oppression, and the representation is not presented publicly as an apt way for out-group members to reference target group members" (2020, 107). In short, to use these paradigmatic examples ${ }^{1}$, reclaiming 'queer' expresses pride in being not-cisgender/not-heterosexual and presents this word to cisgender, heterosexual people as an appropriate way of referring to not-cisgender/not-heterosexual people, while reclaiming the n-word expresses camaraderie and solidarity between Black people in defiance of racism and this word is not presented to non-Black people as an appropriate way of referring to Black people.

Jeshion (2020) notes that reclamation is a complex linguistic and social process which involves numerous individual and collective acts performed and interpreted within the relevant communities and that this process

1 Among other examples used by Jeshion are 'Black' for pride reclamation and 'bitch' for insular reclamation. 
extends through a long period of time. She characterizes the diachronic structure of the process of slur reclamation, as it is often characterized for other instances of linguistic change, as having four stages:

I) Preliminary state: the word is governed by linguistic conventions $\mathrm{C}$ regarding its meaning, pragmatic use, primary associations.

II) Acts of linguistic creativity and innovation: speakers use the word in novel ways, departing from $\mathrm{C}$, sometimes with the deliberate aim to effect change, sometimes not.

III) Acts of imitation and diffusion: speakers imitate the novel uses or key aspects of them.

IV) End result: the word has come to be governed by new linguistic conventions $\mathrm{C}^{\prime} \neq \mathrm{C}$; the word may still retain its former conventions $\mathrm{C}$, becoming polysemous, or $\mathrm{C}$ may be supplanted by C'. (Jeshion 2020, 108)

Jeshion characterizes initial reclamatory acts as those which ignite the reclamation process (stage 2) and secondary reclamatory acts as imitative and parasitic on the previous ones (stage 3). During the reclamation process slurs are polysemous, often for a long time, and they retain the linguistic conventions encoding derogation while simultaneously acquiring the nonderogatory ones. Initial reclamatory acts consist of speakers intentionally breaking and altering the linguistic conventions in order to change the oppressive social norms justifying and manifested by the slur. The speakers imitating the initial reclaimers do not necessarily have such intentions but their uses are still a part of the reclamation process and of the emancipatory movement. Jeshion states that "aiming to break linguistic conventions to shift oppressive social norms that are manifested and perpetuated by linguistic representations is a key ingredient to acts of reclamation" (2020, 111), taking the speakers' intentions to play a big part in the initiation of the reclamation process. Usually, in the initial acts of reclamation the speakers aim to undermine the slur's conventional function as a weapon by hijacking it and using it in a positive way.

Jeshion claims that initial pride reclamatory acts and initial insular reclamatory acts differ. She writes that in the pride ones the members of the target group intentionally and consciously use the slur in a novel way to 
change the dominant negative attitudes towards them. Using the slur the "speakers self- and group-reference while overtly manifesting an attitude of pride for being in the target group" $(2020,121)$. These acts are acts of selfand group-affirmation - the slur becomes the group identity-label. On the other hand, in insular reclamatory acts the target group members use a slur in a novel way but not necessarily with a conscious goal of responding to or transforming the dominant negative attitudes present in the society. Jeshion claims that even though the initial acts are similar to ordinary apolitical in-group uses of unreclaimed slurs (similar to mock insults between friends), "later acts quickly become intentionally political" (2020, 121). According to Jeshion, acts of imitation are often performed with an awareness of their political power and aimed at achieving a sense of solidarity. In opposition, pride reclamatory acts are direct and sincere and not mocking or ironic. Jeshion claims that while such acts might combine manifesting pride with expressing disdain or mockery of bigotry, "the latter [is] not necessary, and often non-existent" (2020, 121, footnote 21$)$. She writes that it is the firstorder use of the slur with the positive polarity that secures the linguistic change. Meanwhile, insular reclamatory acts mock the derogation present in the slur uses and ridicule it into a term manifesting camaraderie.

According to Jeshion, the semantic change achieved through the process of slur reclamation begins with acts of linguistic innovations generating meaning-transformations. She claims that initial pride reclamatory acts achieve amelioration by connecting the slur with paralinguistic cues and positive associations: "speakers express pride or group-self-respect through overt statements, but also intonation, gesture, body language, visibility when the norm is the closet or silence" $(2020,125)$. To put it differently, in pride reclamatory acts the speakers introduce transformed slur meanings (to be secured by the widespread use and conventionalisation) by using the slur while communicating (directly or indirectly) pride in belonging to the target group. Meanwhile, initial insular reclamatory acts involve verbal irony, which can be emphasized by amelioration via paralinguistic cues and positive associations. In short, initially insular reclamatory acts are ironic uses of the slur aimed at communicating camaraderie. After such uses become widespread and conventionalized the slur "shifts polarity and becomes a social deictic for communicating camaraderie" $(2020,125)$. 
The difference between pride and insular reclamation is crucial to Jeshion's description of secondary uses of reclaimed slurs. She claims that while this may differ between particular slurs, in pride reclamation secondary outgroup use becomes permissible and in insular reclamation it is generally prohibited. In the case of pride reclamation initial acts present the slur as a group-adopted identity label which, along the normalization through ingroup imitation, amounts to the target group tacitly authorizing out-groups to use the reclaimed slur as an appropriate way to refer to the target-group. In the case of insular reclamation, the target group does not adopt the slur as a group identity-label and the widespread in-group uses do not authorize out-group use. On the contrary, according to Jeshion, in-group uses function to communicate camaraderie in the shared experience of discrimination towards the target group and therefore prohibit out-group uses.

\section{Bianchi's Echoic view}

Bianchi (2014) offers an echoic account of slur reclamation. According to her view, when the members of the target group use the relevant slur in a reclamatory way, they echo the derogatory uses and manifest their dissociation from the derogatory contents. This view is supposed to account for the fact that appropriative uses of a slur are typically available only for the members of the targeted group, although they can be extended to selected non-members in highly regulated situations.

What is worth noting is that Bianchi distinguishes between two types of contexts of in-group non-derogatory uses of slurs that are supposed to demarcate the group and show a sense of intimacy and solidarity. These are the friendship contexts, where there is no conscious political intent, and the appropriation contexts, where target groups reclaim the use of the slur as a deliberate socio-political action or artists belonging to the group attempt appropriation as a way of subverting the oppressive socio-cultural norms. Bianchi's distinction differs from Jeshion's (2020) distinction between pride reclamation and insular reclamation - although, on the face of it, the latter resembles Bianchi's friendship contexts. While both Bianchi's and Jeshion's distinctions focus on the speaker's intention, for Bianchi the friendship and appropriative contexts differ in terms of the lack or presence of conscious 
socio-political intent. Most importantly, Jeshion distinguishes between the reclamation of slurs claiming that, e.g., 'queer' falls into the category of pride reclamation while the n-word falls into the category of insular reclamation, whereas Bianchi distinguishes between friendship and appropriative uses of slurs. Throughout the paper Bianchi rarely differentiates between these two contexts and refers to reclamatory uses as community uses of slurs.

What is crucial for Bianchi's view is that it accounts for non-derogatory uses of slurs (including reclamation) without postulating meaning change. The echoic account of slur reclamation is based on the echoic uses of language as they are defined in the Relevance Theory introduced by Wilson and Sperber (1986). According to the Relevance Theory, we can distinguish between descriptive and interpretive uses of language. A descriptive use of an utterance or a thought represents a state of affairs in the word, while an interpretive use represents the (actual or possible) utterance/thought of another person concerning a state of affairs. An example of an interpretive use of language is an indirect speech report. Echoic uses are a subset of interpretive uses in which a speaker both represents an attributed utterance/thought and informs (e.g., via intonation, facial expressions or other context cues) the hearer of their attitude towards that utterance or thought. Ironic uses are those echoic uses in which the speaker's attitude towards the attributed content is dissociative. Bianchi claims that in the case of ironic uses the speaker expresses a dissociative attitude either towards an actual or possible utterance/thought attributed to another person or towards (cultural, moral, social, etc.) expectations and norms.

Bianchi proposes an echoic account of slur reclamation-reclamatory uses echo derogatory uses in ways that manifest their dissociation from the offensive contents expressed or conveyed by slurs. She claims that often these are ironic uses in which the speaker attributes utterances or thoughts to others in order to express a critical attitude. Bianchi emphasizes that this attitude might differ between speakers, ranging from "playful puzzlement to powerful condemnation, from joyful mockery to hash rejection, and so on" $(2014,40)$. Cepollaro (2020) further develops Bianchi's echoic view and offers insightful remarks on the power of irony writing that "[i]n ridiculing and mocking the bigot's perspective by using their own words, the 
speaker puts herself in a position of superiority: she steals a weapon and refuses to surrender to discrimination and prejudice; she refuses to be just a suffering victim or a powerless witness of hate speech and instead resists by subverting linguistic conventions" (2020, 90-91).

Bianchi provides an example of friendship context - in which members of the target-group use the slur non-offensively in order to express a sense of closeness and solidarity with no conscious socio-political intent-where two gay friends, $\mathrm{Al}$ and Bob, talk about a new colleague, Tom, and $\mathrm{Al}$ utters (1):

(1) I'm sure Tom is a faggot.

In this scenario, Al uses the slur 'faggot' to echo a representation with a conceptual content - "a cultural, moral or social norm stating that homosexuals deserve derision or contempt" (Bianchi 2014, 40). Al communicates his own dissociative attitude towards this homophobic norm and suggests that the idea that gay people deserve contempt is false, stupid, inappropriate, bad, shameful, etc.

What may seem like a problem for Bianchi's account is that in such non-derogatory uses as in (1), the speaker does assert something. By uttering (1), Al not only mocks the homophobia represented in the slur 'faggot', but also represents a state of affairs such that he is sure that Tom is gay. Bianchi claims that indeed in such uses the speaker commits oneself to the assertion of the sentence with a neutral counterpart in the place of the slur, but not to the offensive content expressed or conveyed by the slur 'faggot'. Furthermore, we could assume that $\mathrm{Al}$ is not echoing a concept but only a constituent of concept-its derogatory component.

One of the last issues that an account of slur reclamation needs to cover is the difference between in-group and out-group uses. Bianchi explains the fact that reclamatory uses are usually only available to the members of the target-group in the following way: "an ironical use requires a context in which the dissociation from the echoed offensive content is clearly identifiable: ceteris paribus, in-group membership is per se strong evidence that the exchange takes place in such a context" $(2014,42)$. While out-groups can have dissociative attitudes towards the slur's derogatory context, it is impossible for them to undoubtedly make this attitude manifest. Even when 
their interlocutors are aware of their attitudes and opinions, anyone who overhears the utterance could take it to be a derogatory one. On the other hand, Bianchi claims that appropriated uses of slurs may extend to outgroups. She claims that selected speakers and highly controlled conditions can create contexts in which the out-groups' dissociation from the derogatory contents is clear. Bianchi claims that this was the case for the word 'queer' - the LGBT+ community authorized the academic community to use this term in an appropriated way.

It needs to be noted that Bianchi does realize that uses of some reclaimed slurs are no longer echoic. She claims that for words such as 'gay' or 'queer' the reclamation process is over and, when that happens, we can say that the meanings of these words has changed (or that the words no longer convey offense). While her account focuses on the linguistic mechanisms of the particular reclamatory uses of slurs and not on reclamation as a process, she does note that when the practice of reclamatory uses "is sufficiently widespread it may extend also to selected out-groups, and affect - diachronically - the slur meaning (expressed or conventionally conveyed)" (2014, $43)$.

\section{The reclamation of 'queer' and of the n-word}

In this section I will discuss some data concerning the reclamation of the slur 'queer' and of the n-word provided by Brontsema (2004) and Rahman (2012). Brontsema (2004) provides a linguistic account of reclamation focusing on the specific case of the term 'queer'. She cites Chen's definition: "The term 'reclaiming' refers to an array of theoretical and conventional interpretations of both linguistic and non-linguistic collective acts in which a derogatory sign or signifier is consciously employed by the 'original' target of the derogation, often in a positive or oppositional sense" $(1998,130)$. I will briefly discuss the history of the reclamation of the word 'queer' provided by Brontsema.

During the 1980s and the early 1990s, the LGBT+ community started to reclaim the term 'queer' which was then the most popular and harmful slur for gay and trans people. The homophobia in the AIDS activism and the increase in anti-gay crimes lead to launching of several activist groups 
including Queer Nation, some of whose members were responsible for the famous "Queers Read This" flyers handed out at the 1990 Gay Pride Parade in New York City (Rand 2014). The flyer urged its readers to take a stand against homophobic and heterosexist institutions, to reclaim the word 'queer' as a form of resistance and join forces under its banner. Reclaiming the word 'queer' was in itself a radical act of highlighting homophobia in order to fight it. The "Queers Read This" flyer underlined the need for direct action and objected to the assimilationist strategies with straightforward statements such as 'Straight people are your enemy.' Reclaiming the term 'queer' set out to unite people of non-normative sexualities and genders, and it was not meant to be used as a synonym for gay and lesbian (Brontsema 2004).

Brontsema claims that there were several uses of the term 'queer' that coexisted (at the time of writing) and that it is not the case that there are only positive in-group uses and negative out-group uses. She discusses the use of the term 'queer' by self-identified queers, in which the term is used inclusively and in opposition to the essentializing 'gay' and 'lesbian', and in which it can be understood as more of an anti-identity than identity. Such use is similar to how the reclaimed meaning of 'queer' was intended in the early 1990s, but the larger society generally failed to understand the nuances of the term and uses it as a synonym of gay and lesbian. Another use of 'queer' is the one appearing in popular television series such as "Queer as Folk" and "Queer Eye for the Straight Guy", focusing on gay men, where it is used rather as a trendy synonym for 'gay'. The reclamation process did not eliminate the derogatory use of 'queer' and during the reclamation process the word continued to be used pejoratively. The last use of 'queer', which also diverges from the radical meaning intended in the initial acts of reclamation, is the contemporary most common meaning of the word - an umbrella term for lesbian, gay, bisexual and transgender people. Today, with the rising awareness of many different sexualities and gender identities, the acronym extends to LGBTQIAP $+^{2}$ or, in a shorter version, to LGBTQ+ where the 'queers' are included in the acronym rather than

2 Meaning: lesbian, gay, bisexual, transgender, queer, intersex, asexual, pansexual. The ' + ' sign is included to emphasize the fact that there are more ways to identify beyond the acronym. 
equated with it. Nevertheless, the term 'queer' is now most commonly understood as "of, relating to, or being a person whose sexual orientation is not heterosexual and/or whose gender identity is not cisgender" (definition taken from the online entry for 'Queer' in the Merriam Webster dictionary at https://www.merriam-webster.com/dictionary/queer).

The history of the term 'Black' is similar to that of the term 'queer'. Brontsema writes that "[t]he history of 'black' shows that revolutionary intent does not predetermine the future of a word, that intent can be betrayed even when a word is said to be 'reclaimed'." (2004, 11). 'Black' was intended to be confrontational, revolutionary and reevaluating Blackness, but when white people became familiar with this term it became just a substitute for the no longer accepted by the Black community term 'Negro'. As in the history of the term 'queer', "[t]he original energy of black was betrayed and subsequently died as it was not used with the same vital radicalism. Instead of forcing racists to confront their hatred and speak it out loud, their racism was simply given a new mask to wear." $(2004,11)$.

Rahman (2012) discusses the history of the n-word. While the early use of the word - dating back to 16th century, borrowed from the Spanish and Portuguese slave traders who used the word 'negro' meaning 'black' —-was a relatively neutral referential term for Black people used by white people, it became a racist slur during the 19th century. The transformation of the n-word into a racial slur came at the time of the movement for the abolition of slavery and the increase of numbers of free African Americans. Rahman claims that the in-group uses of the n-word developed within the slave community. This variation of the n-word in the African American community can be distinguished by its pronunciation - in African American English the form of the word ends in a schwa, without $/ \mathrm{r} /$. Rahman notes that the "social meanings developed among the Africans (...) reflected a view in which they saw themselves as survivors and as humans whose freedom and dignity had been assaulted" $(2012,146)$. During the time of slavery, the nword had developed social meanings related to survival - it was a term that Africans used to refer to themselves and others in the struggle to survive and using it emphasized the identity of the speaker as participating in the culture of survival. 
In other words, the reclaimed n-word has a core meaning which has been established through generations which relates to survival. Rahman notes that additional but related attitudinal aspects of meaning can layer over the core, such as the solidarity meaning which "emerges through common understanding and shared experiences related to survival" $(2012,155)$, or the hip-hop community use of the n-word which "underlies projection of an identity that directly and overtly rejects racist uses of [the n-word] while declaring self-pride and independence" $(2012,159)$. It is worth noting that while the positive uses of the n-word were present in the African American community long before the emergence of the hip-hop community uses, in the last decades of the 20th century these uses became much more widespread because young African Americans in the hip-hop community took ownership of the racist n-word and transformed it into their own positive version of the n-word ending in '-a' instead of '-er'.

The reclamation processes are complex and nuanced, both in the case of reclaimed slurs used only by in-groups and in the case of reclaimed slurs open to out-groups. In the next section I will present a view of slur reclamation that accounts for the data provided by Brontsema (2004) and Rah$\operatorname{man}(2012)$.

\section{Combining the Echo and Polysemy views}

I want to propose a view of slur reclamation that accounts for the meaning-change without omitting the crucial pragmatic steps, which is motivated by the histories of reclaimed slurs presented in section 4. I take Jeshion's (2020) and Bianchi's (2014) accounts of reclamation to be insightful descriptions of different stages of the reclamation process; however, neither account tells the whole story of slur reclamation. Treating the Polysemy and Echoic views as rivals is mistaken and combining the two can account for the linguistic evidence concerning slur reclamation. ${ }^{3}$ Furthermore, I believe that such an account can be useful for studying semantic change in general.

3 I am not alone in this stance (see Cepollaro 2020 for a view of slur reclamation that incorporates both the mechanism of echo and polysemy). I agree with Cepollaro 
The main reason why Bianchi's (2014) view is not enough to explain slur reclamation is the fact that it does not account for meaning change, although she does note that a widespread echoic use of a slur can give rise to polysemy. Jeshion argues against the echoic view writing that "because ironic echoic utterances of slurs leave intact slurs' weapon meanings, they do not enact any linguistic innovation, and consequently the theory doesn't explain the mechanisms by which pride- and insular-reclaimed slurs become neutralized" $(2020,134)$. To me, the fact that Bianchi's account cannot account for meaning change is not an objection against her view, but rather a motivation for incorporating her analysis of reclamatory uses into a bigger picture of slur reclamation. Bianchi herself notices that some reclaimed slurs no longer have an ironic component, but she does not explain how that happens. There seem to be two basic possibilities compatible with the echoic account: either the irony gets conventionalized as part of the slur's meaning; or the non-derogatory use of the slur becomes so widespread that the need for distorting the derogation vanishes. Both seem unsuited for explaining the subversive reclamatory acts of self- or group-identification with the slur. However, the echoing of the slur's derogatory content is a necessary step in slur reclamation.

A disadvantage of Jeshion's view, which can be generalized to polysemy views as such, concerns neglect of the pragmatic mechanisms necessary for the new linguistic conventions to emerge. This neglect amounts to Jeshion's (2020) inadequate description of the reclamation of 'queer' and 'Black'. As it was shown in the previous section, the actual initial intent was to use these words in a radical confrontational manner which was to be achieved through keeping the derogatory content of the slur detectable while subverting it and thereby disarming it. To consider this as simply an act of linguistic innovation omits certain crucial features of the initial reclamatory acts. Again, this is not an argument against Jeshion's view of reclamation, but a reason to refine and develop it. Acknowledging the meaning-transformational power of pragmatic mechanisms can also help with accounting for the fact that the outcome of the slur reclamation can often differ from the intent behind the initial reclamatory acts - as in the cases of 'queer' and

that while the reclamation process starts with echo, the echoic framework cannot explain how the global meaning of a reclaimed slur changes. 
'Black'. In the following paragraphs, I present an account of slur reclamation which starts from Jeshion's view and enriches it with pragmatic mechanisms.

Following Jeshion, I want to characterize the stages of slur reclamation explaining at the same time how the slurs come to have new meaning. These stages are characterized as follows:

(1) Preliminary state: the slur is governed by linguistic conventions C regarding its meaning, pragmatic use, primary associations.

(2) Echoic uses of the slur: in-group speakers echo the slur's derogatory content manifesting their dissociative attitudes towards it.

(3) Self- or group-identification: in-group speakers self- or group-identify with the echoic use of the slur. Initiation of a new linguistic convention C'.

(4) Acts of imitation and diffusion: in-group speakers imitate the selfor group-identification uses or key aspects of them. Securing of the linguistic convention C'.

(5) Out-group recognition: the linguistic convention C' reaches the outgroup. Various possibilities: (i) C' is adopted by out-groups; (ii) C' is recognized but not adopted by out-groups; (iii) C' is transformed into another linguistic convention C" by the out-groups.

(6) Possible end results: (i) polysemy - different linguistic conventions coexist; (ii) replacement-C' or C"' supplants C.

Before explaining this process, let me note that at each stage the necessary action for completing the reclamation process may not happen, due to various reasons such as the existence of power imbalances in society, the invisibility of the target group, legislation discriminating against the target group, etc. Moreover, reclamation is a complex process which requires various contextual as well as cultural, social, and political conditions to be successful. ${ }^{4}$

In the first stage the slur has derogatory content and is used to harm the target group. That is the starting point of any reclamation process. In the second stage I make use of Bianchi's Echoic approach - the members of the target group start using the slur in an echoic way. The speakers, often angry because of being called with the slur and/or disagreeing with the

4 See Herbert (2015) for an insightful analysis of how risky the attempts at reclamation are and what negative consequences they might bring about. 
discrimination it connotes, echo the derogatory content of the slur expressing a dissociative attitude towards it. What is important to note is that the dissociative attitudes can vary across speakers and range from mere ridiculing to hateful contempt. During the second stage the meaning of the slur remains intact, as the dissociation from the derogation is achieved by pragmatic mechanisms.

The third step is the self- or group-identification with the echoic use of a slur - the target group members already familiar with the echoic uses of the slur take these uses (mocking, condemning, denouncing the derogatory content of the slur) and associate themselves with them. This step is what makes the reclamatory acts revolutionary, and this is indeed what happened in the cases of 'queer' and the n-word. The acts initiating the new meaning of 'queer' were acts of displaying rage towards homophobia and "queerbashing". The acts initiating the new meaning of the n-word in the 1800 s were acts of displaying solidarity in the face of oppression. The self- or groupidentification with echoing the slur's derogatory content introduces a new linguistic convention which includes the slur's new subversive meaning. I take this positive act to be what makes reclamation a case of meaning change, as it is no longer only a dissociation from the derogatory content of the word but rather an introduction of a new content associated with the word. ${ }^{5}$ While the mechanism of self- or group-identification is similar to what Jeshion (2020) describes as the Identity Ownership ${ }^{6}$ feature of reclamation, the difference lays in what the speakers take to be a part of their identity. On my account, that is the echoing of the derogatory content of a slur, and not simply the reversed-polarity version of the slur. ${ }^{7}$

5 I follow Jeshion in taking the "novel first-order uses of the slur" $(2020,134)$ to be necessary for the introduction of a new linguistic convention or, in other terms, a new local meaning.

${ }_{6}$ Jeshion (2020) takes Identity Ownership to be one of the central features of reclamation. She claims that the speakers use the reclaimed slur as an identity-label "as a means to socially group self-define on their own terms" $(2020,122)$ and at the same time they use the reclaimed slur "as a means to reverse derogating social attitudes and norms on the group" (2020, 123).

7 Polarity Reversal is another central feature of reclamation on Jeshion's (2020) account: "speakers use representations that standardly have a negative polarity to communicate a positive polarity" (2020, 122). 
The fourth step secures the linguistic convention introduced in the third step. If the new use of the slur becomes widespread enough among the target-group members, the new local meaning is secured. It is important to note here that there might be more than one new meaning introduced in the third step. The target groups are not homogeneous and can differ with respect to their attitudes towards the slurs and to their willingness to identify with them. This is, again, noticeable in the histories of 'queer' in which different reclamatory meanings collide (the confrontational 'queer' vs. the umbrella term 'queer') and of the n-word in which many members of the target group categorically oppose to the reclamatory efforts. The idea that by the fourth stage there can be multiple local reclamatory meanings of a slur can be explained by using Anderson's (2018) employment of the notion of communities of practice $e^{8}$ into analyzing slur uses. There can be many communities of practice within groups such as "African Americans" or "American LGBT activists" and therefore there can be many local reclamatory meanings of the n-word or of 'queer'. In the case of the n-word, the initial reclamatory meaning that developed in the enslaved community (see Rahman 2012) was local - enslavers and other white people were not aware of this meaning. As the reclamatory use of the n-word became more widespread, the mainstream started to acknowledge the other meaning which lead to polysemy - one global meaning of the n-word is derogatory, and the other global meaning is the reclaimed, positive one. In the case of more than one meaning introduced in the third stage, it is possible that during the fourth stage one of them will supplant the others or that more than one meaning introduced by in-group self- or-group identification will move onto the fifth stage.

It is only in the fifth step that the reclamatory meanings of the slur enter the mainstream. This does not mean that no out-groups have heard

\footnotetext{
8 Anderson (2018) cites Eckert and McConnell-Ginet's (1992) definition of communities of practice: "An aggregate of people who come together around mutual engagement in an endeavor. Ways of doing things, ways of talking, beliefs, values, power relations - in short, practices - emerge in the course of this mutual endeavor. As a social construct, a community of practice is different from the traditional community, primarily because it is defined simultaneously by its membership and by the practice in which that membership engages." $(1992,464)$
} 
the new use or even understood the new meaning of the slur. During the fifth stage of slur reclamation the new, reclaimed meaning of the slur becomes widely recognized by the public. The new meaning might become recognized but not adopted by the out-groups, as in the case of the n-word; it can become recognized and adopted by the out-groups, as in the case of 'gay'; or it can become adopted and therefore transformed because of being no longer a revolutionary term, as in the cases of 'queer' and 'Black'. It is simply impossible for the widely accepted terms to be revolutionary. In the case of more than one meaning entering the mainstream, which one of them supplants the others depends on the uptakes and the power balance - e.g., the term 'queer' as an umbrella term is less controversial and safer for the heterosexual majority than its confrontational meaning. Herbert's (2015) analysis of the risks of attempting to reclaim slurs can illuminate the process in which a revolutionary local meaning of a reclaimed slur loses its revolutionary connotation when entering the mainstream, as in the cases of 'queer' and 'Black'. For the mainstream (e.g., white people or cisgender, heterosexual people), the revolutionary meaning of the reclaimed slur is a threat to their privileged social position. The mainstream can accept a neutral, descriptive meaning of a reclaimed slur but not the revolutionary, subversive, and powerful meaning that is aimed at changing the oppressive social norms which put the targeted group in a worse social position. Herbert focuses on the cases in which a speaker attempts to use a slur in a reclamatory way and yet the audience does not recognize this speech act as reclamatory but as a standard derogatory use of a slur. Here is how she explains the negative consequences of failed attempts at reclamation: "The way the act is taken up determines the force of the act, even when this force is contrary from the original intent of the speaker. When attempts at reclamation fail, context and convention lead a hearer to give uptake to the speech act as deploying a traditional use of the slur. The force of this traditional use is to validate and re-entrench the very norms the act was intended to subvert." (Herbert 2015, 32). While I do agree with this description of reclamatory speech act failure, I believe that even more often the audience (especially people that would characterize themselves as "allies") recognizes that the speaker does not use the slur in the traditional derogatory way but fails to recognize the revolutionary nature of the speech act and the positive 
evaluation encoded by the reclamatory use. The uptake distorts the intended subversive speech act ${ }^{9}$ into a neutral one, and with widespread distortive uptakes and imitation the slur's reclaimed meaning ends up descriptive and hence nonthreatening to the out-groups. ${ }^{10}$

In the last stage we obtain the end result of the reclamation process which can either be polysemy or replacement. In the polysemy end result, the slur has both the derogatory meaning it had in the first stage and the reclaimed meaning recognized by the public, as in the case of the n-word. In the replacement end result, the reclaimed meaning recognized by the public replaces the derogatory one, as in the cases of 'Black' and 'gay'.

\section{Conclusion}

In this paper, I set out to investigate slur reclamation. Jeshion's (2020) Polysemy view and Bianchi's (2014) Echoic view were discussed and the histories of the reclamation of 'queer' and of the n-word were presented. I argued for incorporating the Polysemy and Echoic views into a Combined view which explains the process of slur reclamation and accounts for the examples of histories of reclaimed slurs. The Combined view accounts for the meaning change of the slur during the process of its reclamation but does not ignore the pragmatic step necessary for the introduction of a new linguistic convention. It also explains why the particular processes of slur reclamation vary with respect to both the initial intent behind the reclamatory acts and the end result of the reclamation.

9 Here my notion of "distorting a speech act" means that the uptake differs from what the speaker intended to do with the speech act. Following Kukla (2014), I take the uptake to be the determinant of what sort of speech act has been made - if the speaker says 'Close the door!' intending to issue an order but the audience takes their speech act to be a request, the speech act in question is in fact a request.

10 A similar process, albeit one that does not influence the local meaning of a reclaimed slur, happens when the out-group audience mistakes the in-group speaker's reclamatory use of a slur as a permission to imitate and use it. The audience recognizes the speech act as reclamatory but fails to recognize that it is prohibited that they use it. 
I believe that the Combined view can be used to investigate meaning change in general, and in particular group identity-labels, differing from slurs, originating in internet slang (such as 'incels') and the acts of eliciting linguistic change rooted in the fight for equality (such as deeming offensive terms inappropriate and proposing new ones, as in replacing 'retarded' with 'intellectually disabled', or feminist language reforms). The latter, sometimes called Ameliorative Projects (see Ritchie 2021), share many characteristics with the process of slur reclamation, but what distinguishes reclamation is the echoing of the derogatory content of a slur in the second stage and the self- and group-identification with the echo in the third stage.

What is yet to be done is a detailed examination of various ongoing, finished or faded processes of slur reclamation, by means of linguistic analysis and experimental work, in order to further test the applicability of the Combined view here proposed.

\section{References}

Anderson, Luvell. 2018. "Calling, Addressing, and Appropriation." In Bad Words: Philosophical Perspectives on Slurs, edited by David Sosa, 6-28. Oxford: Oxford University Press. 10.1093/oso/9780198758655.003.0002

Bianchi, Claudia. 2014. "Slurs and Appropriation: An Echoic Account." Journal of Pragmatics 66: 35-44. https://doi.org/10.1016/j.pragma.2014.02.009

Brontsema, Robin. 2004. "A Queer Revolution: Reconceptualizing the Debate Over Linguistic Reclamation." Colorado Research in Linguistics 17 (1): 1-17. https://doi.org/10.25810/dky3-zq57

Cepollaro, Bianca. 2020. Slurs and Thick Terms. When Language Encodes Values. Maryland: Lexington Books.

Chen, Melinda Yuen-Ching. 1998. "I am an Animal!': Lexical Reappropriation, Performativity, and Queer." In Engendering Communication: Proceedings from the Fifth Berkeley Women and Language Conference, edited by Suzanne Wertheim, Ashlee C. Bailey, and Monica Corston-Oliver, 128-40. Berkeley, CA: Berkely Women and Language Group.

Eckert, Penelope, and Sally McConnell-Ginet. 1992. "Think Practically and Look Locally: Language and Gender as Community-Based Practice." Annual Review of Anthropology 21 (1): 461-88. 10.1146/annurev.an.21.100192.002333

Herbert, Cassie. 2015. "Precarious Projects: The Performative Structure of Reclamation." Language Sciences 52: 131-8. https://doi.org/10.1016/j.langsci.2015.05.002 
Jeshion, Robin. 2020. "Pride and Prejudiced: on the Reclamation of Slurs." Grazer Philosophische Studien 97 (1): 106-37. https://doi.org/10.1163/1875673509701007

Kukla, Quill. 2014. "Performative Force, Convention, and Discursive Injustice." Hypatia 29 (2): 440-57. https://doi.org/10.1111/j.1527-2001.2012.01316.x

Rahman, Jacquelyn. 2012. "The N Word: Its History and Use in the African American Community." Journal of English Linguistics 40 (2): 137-71. https://doi.org/10.1177/0075424211414807

Rand, Erin J. 2014. Reclaiming Queer: Activist and Academic Rhetorics of Resistance. University of Alabama Press.

Ritchie, Katherine. 2021. "Essentializing Language and the Prospects for Ameliorative Projects." Ethics 131 (3): 460-88. https://doi.org/10.1086/712576

Sperber, Dan, and Deirdre Wilson. 1986. Relevance: Communication and Cognition. Oxford: Basil Blackwell. 